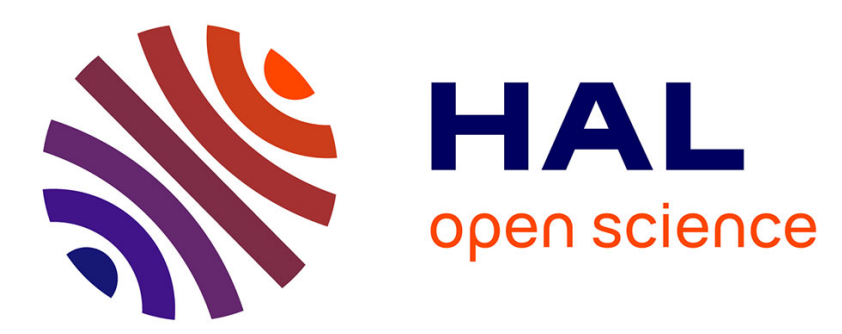

\title{
Competition between pi-pi or furan-perfluorophenyl stacking interactions in conjugated compounds prepared from azomethine connections
}

Charlotte Mallet, Magali Allain, Philippe Leriche, Pierre Frère

\section{- To cite this version:}

Charlotte Mallet, Magali Allain, Philippe Leriche, Pierre Frère. Competition between pi-pi or furanperfluorophenyl stacking interactions in conjugated compounds prepared from azomethine connections. CrystEngComm, 2011, 13 (19), pp.5833-5840. 10.1039/c1ce05575e . hal-03344566

\section{HAL Id: hal-03344566 \\ https://univ-angers.hal.science/hal-03344566}

Submitted on 15 Sep 2021

HAL is a multi-disciplinary open access archive for the deposit and dissemination of scientific research documents, whether they are published or not. The documents may come from teaching and research institutions in France or abroad, or from public or private research centers.
L'archive ouverte pluridisciplinaire HAL, est destinée au dépôt et à la diffusion de documents scientifiques de niveau recherche, publiés ou non, émanant des établissements d'enseignement et de recherche français ou étrangers, des laboratoires publics ou privés. 


\title{
Competition between $\pi-\pi$ or furan-perfluorophenyl stacking interactions in conjugated compounds prepared from azomethine connections $\dagger$
}

\author{
Charlotte Mallet, Magali Allain, Philippe Leriche and Pierre Frère* \\ Received 17th May 2011, Accepted 21st June 2011 \\ DOI: 10.1039/c1ce05575e \\ Conjugated compounds associating phenyl or pentafluorophenyl units linked via azomethine bonds to \\ a central furan or furylene-vinylene moiety have been synthesized. The crystal structures of compounds \\ end capped with perfluorophenyl units are analyzed in terms of intermolecular interactions involving \\ the $\mathrm{C}-\mathrm{H}---\mathrm{F}$ contacts, $\pi-\pi$ interactions and furan-perfluorobenzene interactions. The compound with \\ a furan moiety as spacer presents a stacking mode defined by $\mathrm{C}-\mathrm{H}----\mathrm{F}$ contacts and $\pi-\pi$ interactions \\ while the compound based on a furylene-vinylene unit shows a packing pattern exclusively due to \\ strong furan-perfluorobenzene interactions.
}

\section{Introduction}

In the field of molecular materials, the control of the crystal structures which determines the physical properties of the materials requires intensive investigations in order to elucidate the relationships between molecular structures and supramolecular architectures. Weak intermolecular interactions such as hydrogen bonding, halogen bonding, $\pi-\pi$ stacking and donoracceptor interactions represent the main tools of crystal engineering. ${ }^{1-7}$ Thus arene-arene interactions between aromatic residues play a key role in the performance of conducting or semi-conducting materials. ${ }^{8,9}$ Since the discovery of the benzenehexafluorobenzene co-crystallization by Patrick and Prosser, ${ }^{10}$ phenyl-perfluorophenyl interactions have been observed for many co-crystals or in crystalline structures of mixed derivatives built with both phenyl and perfluorophenyl groups. ${ }^{11-19}$ Such interactions, often resulting in eclipsed or staggered face to face $\pi-\pi$ stacking, are the main driving forces for the self-organization of the molecules in those solids. Although the understanding of the role of the fluorine atoms is not yet clear, many theoretical and experimental works have shown that the arene-perfluoroarene interactions could be considered as an interesting supramolecular tool for crystal engineering. ${ }^{20}$ By contrast with the great number of studies devoted to the arene-perfluoroarene interactions, the works to elucidate the interactions between perfluorophenyl and heterocycle units are surprisingly limited. In the field of organic semiconductor materials, a recent trend consists of associating perfluoroarene and thiophene units in order to enhance the electron affinity of corresponding

LUNAM Université, University of Angers, MOLTECH-Anjou UMR CNRS 6200, SCL group, 2 boulevard Lavoisier, 49045 Angers, France. E-mail: pierre.frere@univ-angers.fr; Fax: +33 241735405; Tel: +33 241735063

$\dagger$ CCDC reference numbers 818758-818760. For crystallographic data in CIF or other electronic format see DOI: 10.1039/c1ce05575e materials. ${ }^{21-27}$ X-Ray analyses of the described structures revealed the formation of mainly two kinds of supramolecular arrangements. In planar perfluoroarene-thiophene oligomers, the stacking of the molecules is promoted by close cofacial interactions between the electron-rich thiophene and the electron-poor perfluoroarene moieties. ${ }^{28,29}$ In contrast, when the perfluorophenyl and thiophene units are not coplanar, the organization shows a discrimination of systems and thiophenes stack together via $\pi-\pi$ interactions and separately from perfluorophenyl units which also interact with each other. ${ }^{24,30}$ Although conjugated systems based on the furan moiety have emerged as a new alternative for the development of semiconducting materials, ${ }^{31,32}$ conjugated systems associating perfluoroarene and furan have been scantly studied. ${ }^{33,34}$ Moreover, furan-perfluorophenyl interactions have not clearly been evidenced yet. There exists a study of furan-fluoroaromatic interactions concerning the intramolecular interactions in (heterocyclo)paracyclophane derivatives ${ }^{35}$ and one example of an X-ray structure of a furan-perfluorophenyl conjugated compound recently published: ${ }^{34}$ however, the stacking mode in the structure was not described. ${ }^{36}$

In the continuation of our current interest in conjugated systems based on furan units as electroactive materials from renewable biomass resources, ${ }^{37-39}$ we present here three conjugated compounds 1, 2 and $\mathbf{3}$ associating furan moieties with phenyl or perfluorophenyl units via azomethine bonds (Scheme 1).

The use of furan cycles and azomethine bonds are part of a green chemistry approach. Thus azomethine bonds are formed by reaction between aldehydes and amines and produce only water as waste. Several examples of conjugated materials based on azomethine have been described. ${ }^{40-47}$

Moreover, furaldehyde and 5-hydroxylmethyl-furfural (HMF) used as starting materials are well known as renewable materials obtained by dehydration of glucose or by transformation of lignocellulosic biomass. ${ }^{48-50}$ 
<smiles>C(=N/c1ccccc1)\c1ccc(/C=N/c2ccccc2)o1</smiles><smiles>Fc1c(F)c(F)c(/C=N/c2ccc(/C=N/c3c(F)c(F)c(F)c(F)c3F)o2)c(F)c1F</smiles><smiles>Fc1c(F)c(F)c(/N=C/c2ccc(/C=C/c3ccc(/C=N/c4c(F)c(F)c(F)c(F)c4F)o3)o2)c(F)c1F</smiles>

Scheme 1 Structures of compounds 1-3.

In this contribution, we report on the electronic properties and on the solid state assemblies in crystals obtained from 1-3 and we show the key role of the furan-perfluorophenyl interactions on the supramolecular organizations of these later.

\section{Results and discussion}

\section{Synthesis}

Compounds 1-3 have been synthesized by condensation of the dialdehyde $\mathbf{4}$ or $\mathbf{5}$ with aniline or pentafluoroaniline (Scheme 2). Dialdehyde $\mathbf{4}$ was synthesized by oxidation of $\mathrm{HMF}^{51}$ while $\mathbf{5}$ was prepared in two steps from furaldehyde. ${ }^{38}$ The easy protocol used for obtaining $\mathbf{1}$, consisting of heating a mixture of $\mathbf{4}$ and aniline without solvent, ${ }^{52}$ could not be used with pentafluoroaniline, firstly because of the low reactivity of its nitrogen atom due to the electron withdrawing effect of the fluorine atoms and secondly because pentafluoroaniline is too volatile to allow long time of reaction or high temperature. The reactions of condensation were efficiently carried out by using a sealed vessel under microwave irradiation. Thus, a mixture of dialdehyde 4 or 5 and 2.2 equivalents of pentafluoroaniline in methylene chloride in the presence of a small amount of $\mathrm{P}_{2} \mathrm{O}_{5}\left(T=80{ }^{\circ} \mathrm{C}\right.$,
$P=4.4$ bar, power $=250 \mathrm{~W}$ ) during $3 \times 10 \mathrm{~min}$ led to target molecules 2 or 3 in $45 \%$ and $38 \%$ yield respectively.

\section{Electronic properties}

The electronic properties of compounds 1-3 have been analyzed by UV-vis spectroscopy and by cyclic voltammetry (CV). Optical and electrochemical properties are gathered in Table 1. The comparison of the UV-vis data of compounds $\mathbf{1}$ and $\mathbf{2}$ shows that the replacement of phenyl terminations by perfluorophenyl units leads to a slight blue shift of the absorption bands probably due to higher torsion of the azomethine bonds. The lengthening of the conjugated system in $\mathbf{3}$ leads to a bathochromic shift of the absorption band corresponding to a decrease of the HOMOLUMO gap from $3.41 \mathrm{eV}$ for 2 to $2.88 \mathrm{eV}$ for $\mathbf{3}$.

The electrochemical properties of compounds 1-3 have been analyzed both in oxidation and reduction. Compound 1 presents two irreversible oxidation processes respectively at 1.26 and 1.54 $\mathrm{V}$ corresponding to the formation of radical cation $\mathbf{1}^{+}$and dication $\mathbf{1}^{++}$. The donating ability of compound $\mathbf{2}$ is strongly decreased due to the presence of the lateral perfluorophenyl groups. Thus this later only undergoes the non-reversible formation of a radical cation at the more anodic potential of 1.49 $\mathrm{V}$. By contrast, the insertion of the furylene-vinylene (FV) unit as spacer in compound 3 enhances the electron donor character and thus allows an easier access to the oxidized states $3^{+}$and $3^{++}$as shown by the two oxidation peaks at 1.18 and $1.47 \mathrm{~V}$.

Table 1 Electronic absorption ${ }^{a}$ and cyclic voltammetry ${ }^{b}$ data of compounds 1-3

\begin{tabular}{llllll}
\hline Compound & $\lambda_{\text {max }} / \mathrm{nm}$ & $\Delta E_{\text {opt }} / \mathrm{eV}$ & $E_{\text {ox } 1} / \mathrm{V}$ & $E_{\text {ox } 2} / \mathrm{V}$ & $E_{\text {red } 1} / \mathrm{V}$ \\
\hline $\mathbf{1}$ & 371 & 3.34 & 1.26 & 1.54 & -1.42 \\
$\mathbf{2}$ & 364 & 3.41 & 1.49 & - & -1.31 \\
$\mathbf{3}$ & 430 & 2.88 & 1.18 & 1.47 & -1.59
\end{tabular}

${ }^{a} 10^{-5} \mathrm{M}$ in $\mathrm{CH}_{2} \mathrm{Cl}_{2}{ }^{b}{ }^{b} 10^{-3} \mathrm{M}$ in $0.1 \mathrm{M} \mathrm{Bu}_{4} \mathrm{NPF}_{6} / \mathrm{CH}_{2} \mathrm{Cl}_{2}, v=200 \mathrm{mV} \mathrm{s}^{-1}$, reference $\mathrm{AgCl} / \mathrm{Ag}$.<smiles>Nc1ccccc1</smiles>

4<smiles>Nc1c(F)c(F)c(F)c(F)c1F</smiles><smiles>Nc1c(F)c(F)c(F)c(F)c1F</smiles><smiles>O=Cc1ccc(C=Cc2ccc(C=O)o2)o1</smiles>

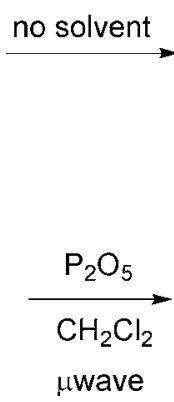<smiles>C(=N/c1ccccc1)\c1ccc(/C=N/c2ccccc2)o1</smiles><smiles>O=C(c1ccc(C=Nc2c(F)c(F)c(F)c(F)c2F)o1)c1c(F)c(F)c(F)c(F)c1F</smiles><smiles>Fc1c(F)c(F)c(/N=C/c2ccc(/C=C/c3ccc(/C=N/c4c(F)c(F)c(F)c(F)c4F)o3)o2)c(F)c1F</smiles>

Scheme 2 Synthesis of oligomers 1-3. 
Compounds 1-3 present a reduction peak corresponding to the formation of radical anion. As expected, the replacement of the phenyl by perfluorophenyl groups allows a rise in the reduction potential from $-1.42 \mathrm{~V}$ for $\mathbf{1}$ to $-1.31 \mathrm{~V}$ for $\mathbf{2}$. The lengthening of the spacer with the donor FV units for $\mathbf{3}$ enhances the reversibility of the reduction process but at a more cathodic potential of $-1.59 \mathrm{~V}$. These results show that the linkage of phenyl or perfluorophenyl groups to furan units by azomethine bonds leads to conjugated systems presenting both donor and acceptor properties. As expected the acceptor character is enhanced by the fluorine atoms, but their electron withdrawing effects are outweighed by the multiplication of the furan units.

\section{Crystal structures}

Slow evaporation of chloroform-ethanol solutions of compounds 1-3 gave single crystals suitable for $\mathrm{X}$-ray diffraction analysis. The details of the data collections are gathered in Table 2.

Compound $\mathbf{1}$ crystallizes in the monoclinic space group $C 2 / c$. Its structure is defined from a half molecule which lies on a twofold axis. As shown in Fig. 1a, the two azomethine bonds are coplanar with the central furan ring and adopt an $E$ configuration and a $\delta$-cis conformation (the nitrogen atoms are oriented in the direction pointing to the oxygen atom). The lateral phenyl rings are not coplanar with the central conjugated system assuming a torsional angle of $38^{\circ}$ with respect to the furan ring.

Table 2 Details of the data collection and structural refinement of 1-3

\begin{tabular}{|c|c|c|c|}
\hline Crystal & 1 & 2 & 3 \\
\hline Formula & $\mathrm{C}_{18} \mathrm{H}_{14} \mathrm{~N}_{2} \mathrm{O}$ & $\mathrm{C}_{18} \mathrm{H}_{4} \mathrm{~F}_{10} \mathrm{~N}_{2} \mathrm{O}$ & $\mathrm{C}_{24} \mathrm{H}_{8} \mathrm{~F}_{10} \mathrm{~N}_{2} \mathrm{O}_{2}$ \\
\hline Molecular weight & 274.31 & 454.23 & 546.32 \\
\hline Temperature/K & 293 & 293 & 293 \\
\hline Crystal system & Monoclinic & Triclinic & Monoclinic \\
\hline Space group & $C 2 / c$ & $P 1$ & $P 2_{1} / c$ \\
\hline$a / \AA$ & $31.930(8)$ & $4.7787(2)$ & $6.4323(9)$ \\
\hline$b / \AA$ & $6.041(2)$ & $6.5029(4)$ & $7.278(1)$ \\
\hline$c / \AA$ & $7.424(1)$ & $13.9073(5)$ & $22.578(4)$ \\
\hline$\alpha / \operatorname{deg}$ & 90 & $78.371(3)$ & 90 \\
\hline$\beta / \mathrm{deg}$ & $97.04(1)$ & $83.747(3)$ & $93.06(1)$ \\
\hline$\gamma / \mathrm{deg}$ & 90 & $87.099(4)$ & 90 \\
\hline$V / \AA^{3}$ & $1421.2(6)$ & $420.60(3)$ & $1055.5(3)$ \\
\hline$Z$ & 4 & 1 & 2 \\
\hline Crystal colour & Colorless & Yellow & Orange \\
\hline$D_{\mathrm{c}} / \mathrm{g} \mathrm{cm}^{-3}$ & 1.282 & 1.793 & 1.719 \\
\hline$F(000)$ & 576 & 224 & 544 \\
\hline$\mu / \mathrm{mm}^{-1}$ & 0.081 & 0.189 & 0.171 \\
\hline Transmission $(\min / \max )$ & $0.553 / 0.998$ & $0.949 / 0.986$ & $0.972 / 0.992$ \\
\hline$\theta(\min / \max ) / \mathrm{deg}$ & $3.43 / 28.05$ & $3.01 / 27.96$ & $3.61 / 29.00$ \\
\hline Data collected & 7548 & 13816 & 19128 \\
\hline Data unique & 1644 & 3764 & 2630 \\
\hline Data observed $[I>2 \sigma(I)]$ & 971 & 2735 & 1397 \\
\hline$R$ (int) & 0.077 & 0.084 & 0.099 \\
\hline Number of parameters & 124 & 297 & 188 \\
\hline$R 1[I>2 \sigma(I)]$ & 0.0577 & 0.0568 & 0.0554 \\
\hline $\mathrm{w} R 2[I>2 \sigma(I)]$ & 0.0943 & 0.1470 & 0.1056 \\
\hline$R 1$ [all data] & 0.1299 & 0.0872 & 0.1308 \\
\hline $\mathrm{w} R 2$ [all data] & 0.1146 & 0.1655 & 0.1339 \\
\hline $\begin{array}{l}\text { Absolute structure } \\
\text { parameter }\end{array}$ & - & $0.1(2)$ & - \\
\hline GOF & 1.108 & 1.049 & 1.061 \\
\hline $\begin{array}{l}\text { Largest peak in final: } \\
\text { difference/e } \AA^{-3}\end{array}$ & $\begin{array}{l}0.151 / \\
-0.211\end{array}$ & $0.401 /-0.323$ & $0.212 /-0.275$ \\
\hline
\end{tabular}

The molecules stack along the $c$ axis in a head to tail overlap of the molecules which prevents $\pi$-interactions between the conjugated systems. The regular distances between the planes formed by the furan rings are about $3.3 \AA$. The molecular organization is mainly defined by $\mathrm{C}-\mathrm{H}---\mathrm{Ph}(d=2.63 \AA$ shown by dotted line in Fig. 1c $)^{53}$ interactions between the phenyl rings which present an edge to face arrangement as observed in crystalline structures of benzene or naphthalene. ${ }^{54}$

The replacement of the phenyl terminations by perfluorophenyl groups leads both to a conformational change and to a strong modification of the interactions that determine the stacking of the molecules. Compound $\mathbf{2}$ crystallizes in the triclinic $P 1$ space group. The molecule is unsymmetrical with an azomethine bond in a $\delta$-cis conformation while the second adopts a $\delta$-trans one (Fig. 2a). The $\delta$-trans conformation presents a better planarity with a torsion angle of the perfluorophenyl of $11^{\circ}$ whereas the torsion of the second perfluorinated cycle reaches $39^{\circ}$. This torsional angle is very close to the value observed in structure $\mathbf{1}$ for the two arms in the same $\delta$-cis conformation.

The view of the structure shows that the molecules stack along the $a$ axis. Between two adjacent columns, molecules are in contact through $\mathrm{C}-\mathrm{H}----\mathrm{F}$ contacts ${ }^{55}$ with $d_{\mathrm{H}---\mathrm{F}}$ distances ranging between 2.50(4) and 2.77(5) $\AA$ as indicated in Fig. $2 b$ by red dotted lines. The stacking of the molecules presents an overlapping of quasi planar conjugated systems involving the $\delta$-trans arm and the furan ring with a slight shift, so that a perfluorophenyl moiety is placed opposite of the azomethine bond of the $\delta$-trans arm (Fig. 2c). The average distance between the conjugated systems is approximately of $3.4 \AA$ which corresponds to classical distances observed for $\pi-\pi$ interactions. The two shortest distances $d_{1}=3.382(4) \AA$ and $d_{2}=3.385(6) \AA$ involve the carbon atoms of the two azomethine links which are in contact with a carbon of furan ring and a carbon of a fluorinated aromatic ring.

At the other end of the molecule, the perfluorophenyl moieties of the $\delta$-cis arms overlap with a shift leading to a superposition of the aromatic ring with the azomethine bond. The distances between the planes of the perfluorinated cycles are close to $3.3 \AA$ and the shortest interatomic distance $d_{3}=3.286(5) \AA$ is observed between the nitrogen atom of an imine linkage and carbon atom of an aromatic ring. A second short distance $d_{4}=3.330(5) \AA$ involves fluorine and carbon atoms of two superposed perfluorophenyl rings. Thus the crystalline arrangement seems to be oriented by a subtle combination of $\pi-\pi$-interactions between conjugated systems and by electrostatic interactions between the electronegative fluorine and nitrogen atoms and the electropositive centre of perfluorinated rings.

The multiplication of the number of furan rings by the insertion of a FV unit as spacer between the two perfluorophenyl rings for 3 strongly modifies the packing mode in the crystal. Compound 3 crystallizes in the centrosymmetric monoclinic space group $P 2_{1} / c$. The structure is defined from a half molecule and the molecule is located on a crystallographic inversion center. As shown in Fig. 3a, the central ethylenic bond is in an $E$ configuration and the two azomethine bonds are in an $E$ configuration and adopt a $\delta$-cis conformation. The two azomethine links are co-planar with the FV unit while the two perfluorophenyl rings assume a torsional angle of $45^{\circ}$ with the plane defined by the central conjugated system. Here the torsional 


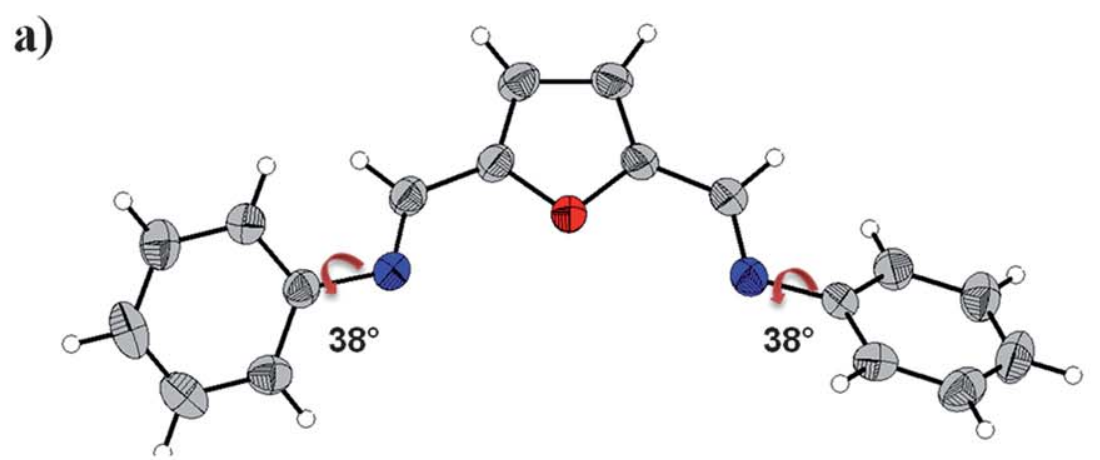

b)

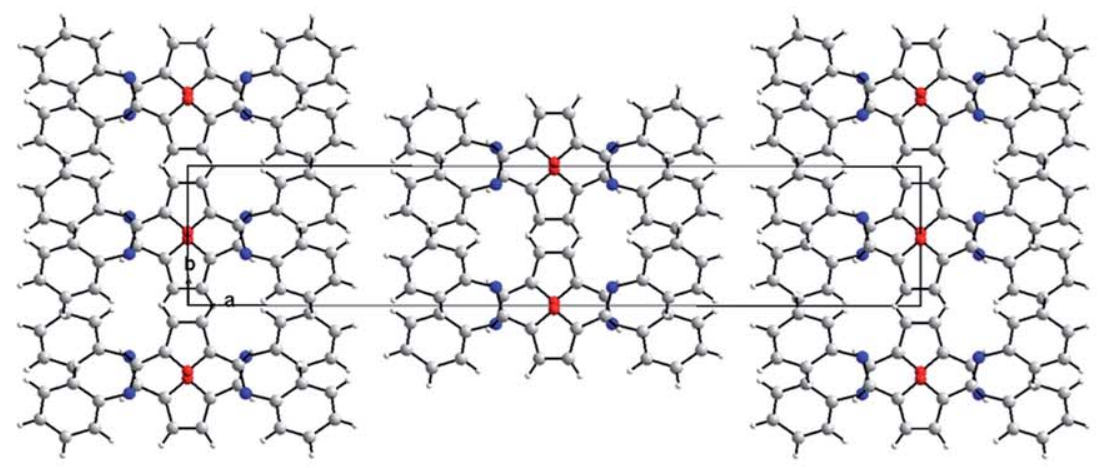

c)

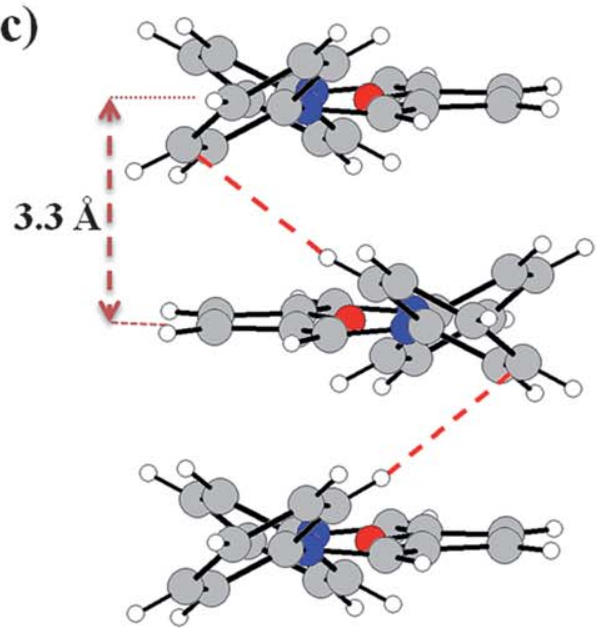

Fig. 1 X-Ray structure of 1. (a) Molecular structure of 1 with anisotropic displacement ellipsoids drawn at the 50\% probability level. (b) Crystal packing of 1 viewed along the cell $c$ axis. (c) Stacking mode of molecules along the $c$ axis, $\mathrm{C}-\mathrm{H}---\mathrm{Ph}$ interactions are shown in dotted lines.

angles are slightly larger than those obtained in structure $\mathbf{1}\left(38^{\circ}\right)$ and $2\left(39^{\circ}\right)$ for the arm in the same $\delta$-cis conformation. The structure shows ribbons of molecules oriented along the $c$ axis which stack along the $b$ axis. The ribbons are linked themselves by $\mathrm{C}-\mathrm{H}----\mathrm{F}$ contacts with $d_{\mathrm{H}---\mathrm{F}}$ distances ranging between 2.38 (3) and 2.73(2) $\AA$ (Fig. 3b). The stacking along the $b$ axis is done so that the furan cycles of a central FV unit of a molecule overlap two perfluorophenyl cycles of two other molecules. The distances between the two planes are about $3.4 \AA$ with several inter-atomic distances ranging between 3.20 and $3.50 \AA$ as shown by dotted lines in Fig. 3c. The centroid to centroid distance measured between perflurophenyl and furan rings is of 3.748(2) $\AA$. This typical face to face stacking, often observed in the structures of mixed fluoroarene-thiophene oligomers or in benzene-perfluorobenzene systems, results from non-covalent interactions between the electron-deficient perfluorophenyl rings and the electron-rich furan cycles. By contrast with the structure of $\mathbf{2}$, such a disposition for $\mathbf{3}$ does not allow any $\pi-\pi$ contact. Thus the lengthening of the conjugated system by insertion of a FV unit strongly favors the multiplication of furan-perfluorobenzene interactions to the detriment of the $\pi-\pi$ interactions.

For a better understanding of the arrangements observed in the X-ray structures of $\mathbf{2}$ and $\mathbf{3}$ and to unravel the role of the fluorine atoms and azomethine bonds in the stacking of the molecules, we investigated the electrostatic potential (ESP) surface $^{23}$ of the two compounds $\mathbf{2}$ and $\mathbf{3}$ by considering the conformations adopted in the structures (Fig. 4). For both compounds, the more negative potential regions (in red) are located on the nitrogen, oxygen atoms and on the fluorine atoms which point to the imine bonds. By contrast the internal part of the hexafluorobenzene and the external part of the central conjugated systems present positive potentials (blue).

As shown in Fig. 4 (right) in the case of $\mathbf{3}$, the superposition of the perfluorobenzene and furan units in the crystal allows the optimization of the interactions between the positive and negative regions. Thus the furan-perfluorophenyl interactions are the main driving forces responsible for the molecular stacking.

For crystal 2, the unsymmetrical conformation of the molecule leads to a slightly different repartition of the charges in the two perfluorinated cycles (Fig. 4 left). The fluorine atoms that are in line with the $\delta$-trans azomethine bond show a less negative potential than the ones of the second perfluorobenzene unit. The slip-stacking of the two $\delta$-trans arms thus mainly implicates $\pi-\pi$ interactions strengthened by small electrostatic character.

In conclusion, we have synthesized new examples of conjugated systems associating furan and perfluorophenyl groups. The comparison of the crystal structures of three compounds varying by the lateral phenyl or perfluorophenyl rings or by the nature of the conjugated spacer evidences the key role of the perfluorophenyl groups in the stacking mode of the molecules. Although compound 1 built with phenyl groups does not present any $\pi$-stacking, the replacement of phenyl by perfluorophenyl 
a)

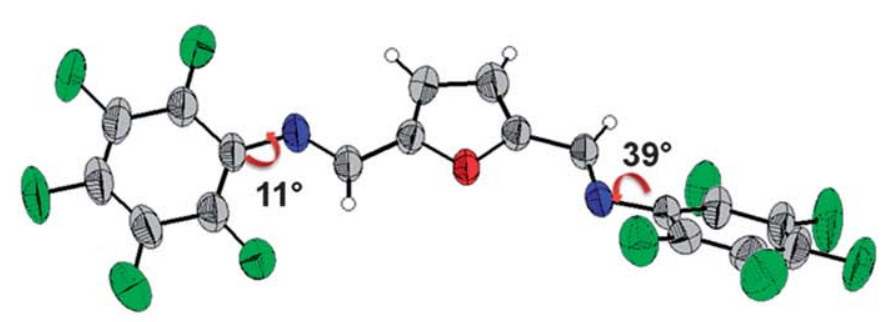

b)

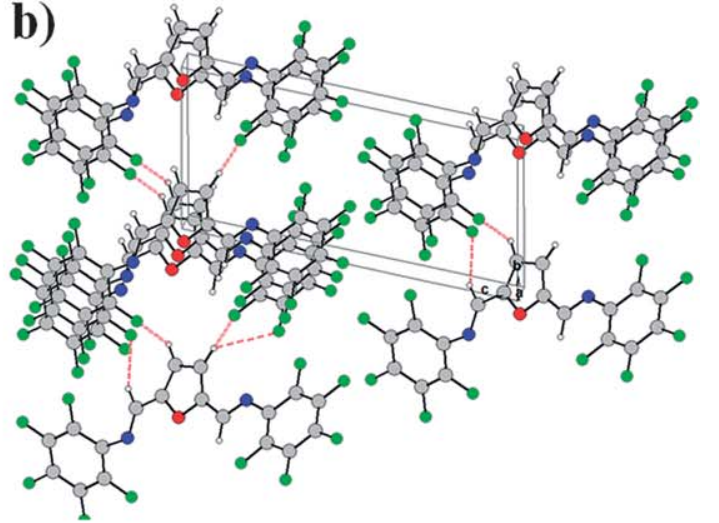

c)

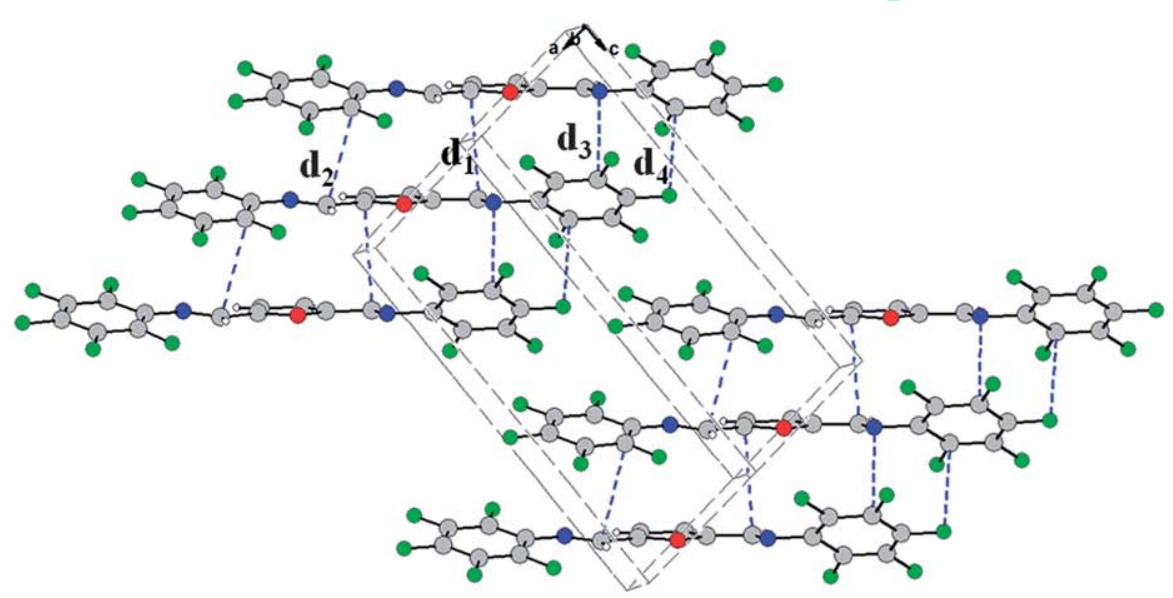

Fig. 2 X-Ray structure of 2: (a) Molecular structure of 2 with anisotropic displacement ellipsoids drawn at the 50\% probability level. (b) Crystal packing of $\mathbf{2}$ showing the intermolecular C--H---F contacts by red dotted lines. (c) Stacking mode in crystal 2, the shortest interatomic distances between overlapping molecules are shown by blue dotted lines.

groups in 2 allows a $\pi$-stacking of the molecules due to subtle combination of $\pi-\pi$ interactions and donor-acceptor interactions. The replacement of the furan by the FV unit as spacer in the conjugated systems leads to the formation of strong furanperfluorophenyl interactions which can be considered as the main driving forces of the packing mode of $\mathbf{3}$ to the detriment of the $\pi-\pi$ interactions.

\section{Experimental}

\section{Syntheses}

2,5-Bis(phenyliminomethyl)furan: $\mathbf{1}^{52}$. A slight excess of aniline was added to a $25 \mathrm{~mL}$ Erlenmeyer flask containing $1 \mathrm{~g}$ of dialdehyde $4(8 \mathrm{mmol})$ at $\mathrm{rt}$. The temperature rapidly rose thus allowing the liberation of water vapor. After $10 \mathrm{~min}$, the brown solid obtained was washed by adding $3 \mathrm{~mL}$ of methanol. The solid was recovered by filtration, recrystallized from methanol to give $2 \mathrm{~g}$ of compound $\mathbf{1}$ ( $91 \%$ yield).

Yellow pale solid, $\mathrm{Mp}=156{ }^{\circ} \mathrm{C}$.

${ }^{1} \mathrm{H} \mathrm{NMR}\left(\mathrm{CD}_{3} \mathrm{COCD}_{3}\right): 8.53(\mathrm{~s}, 2 \mathrm{H}), 7.43\left(\mathrm{t}, 4 \mathrm{H},{ }^{3} \mathrm{~J}=4.8 \mathrm{~Hz}\right)$, $7.33\left(\mathrm{~d}, 4 \mathrm{H},{ }^{3} \mathrm{~J}=4.2 \mathrm{~Hz}\right), 7.28-7.25(\mathrm{~m} 4 \mathrm{H})$.

${ }^{13} \mathrm{C}$ NMR $\left(\mathrm{CD}_{3} \mathrm{COCD}_{3}\right): 154.6,151.5,147.9,129.3$ (2C), 126.6, 121.2 (2C), 117.1.

MS MALDI-TOF: calcd. for $\mathrm{C}_{18} \mathrm{H}_{14} \mathrm{ON}_{2}$ 274.1; found $274.6(\mathrm{M})$.
2,5-Bis(pentafluorophenyliminomethyl)furan: 2. A $10 \mathrm{~mL}$ tube equipped with a magnetic stirring bar was filled with $75 \mathrm{mg}$ of dialdehyde $4(0.6 \mathrm{mmol}), 320 \mathrm{mg}$ of perfluoroaniline $(1.7 \mathrm{mmol})$ in $2 \mathrm{~mL}$ of $\mathrm{CH}_{2} \mathrm{Cl}_{2}$ and $50 \mathrm{mg}$ of $\mathrm{P}_{2} \mathrm{O}_{5}$. The tube was sealed with a rubber cap and irradiated three times for $10 \mathrm{~min}$ at $80^{\circ} \mathrm{C}$ and under a pressure of 4.4 bar with a power reactor of $200 \mathrm{~W}$. The mixture was cooled to room temperature, poured on $20 \mathrm{~mL}$ of water, extracted twice with $\mathrm{CH}_{2} \mathrm{Cl}_{2}(2 \times 20 \mathrm{~mL})$ and the organic phase was dried on $\mathrm{MgSO}_{4}$. After evaporation of the solvent the residue was purified by flash chromatography on silica gel in the presence of several drops of triethylamine (petroleum ether $\left.\left(40-60{ }^{\circ} \mathrm{C}\right) / \mathrm{CH}_{2} \mathrm{Cl}_{2}, 1 / 1\right)$ to give $125 \mathrm{mg}(0.27 \mathrm{mmol})$ of compound 2 ( $45 \%$ yield).

Yellow solid, $\mathrm{Mp}=98^{\circ} \mathrm{C}$.

${ }^{1} \mathrm{H} \mathrm{NMR}\left(\mathrm{CD}_{3} \mathrm{COCD}_{3}\right): 8.59$ (s, 2H), 7.34 (s, 2H).

${ }^{13} \mathrm{C} \mathrm{NMR}\left(\mathrm{CD}_{3} \mathrm{COCD}_{3}\right): 156.6,154.2,120.5$.

${ }^{19} \mathrm{~F}$ NMR $\left(\mathrm{CD}_{3} \mathrm{COCD}_{3}\right):-154.5(\mathrm{dd}, 4 \mathrm{~F}, J=21 \mathrm{~Hz}$, $J=5 \mathrm{~Hz}),-162.4(\mathrm{t}, 2 \mathrm{~F}, J=21 \mathrm{~Hz}),-165.6(\mathrm{dt}, 4 \mathrm{~F}, J=21 \mathrm{~Hz}$, $J=6 \mathrm{~Hz}$ ).

MS MALDI-TOF: calcd. for $\mathrm{C}_{18} \mathrm{H}_{4} \mathrm{ON}_{2} \mathrm{~F}_{10}$ 454.02; found $454.94(\mathrm{M}+\mathrm{H})$.

Elemental analysis for $\mathrm{C}_{18} \mathrm{H}_{4} \mathrm{ON}_{2} \mathrm{~F}_{10}$ : calcd. C 47.60, $\mathrm{H} 0.89$, N 6.17; found C 47.28, H 1.01, N 5.99.

1,2-Bis(5-pentafluorophenyliminomethyl-furyl)- $E$-ethene: 3 . A $10 \mathrm{~mL}$ tube equipped with a magnetic stirring bar was filled with $0.13 \mathrm{~g}$ of dialdehyde $5(0.6 \mathrm{mmol}), 320 \mathrm{mg}$ of perfluoroaniline 
a)

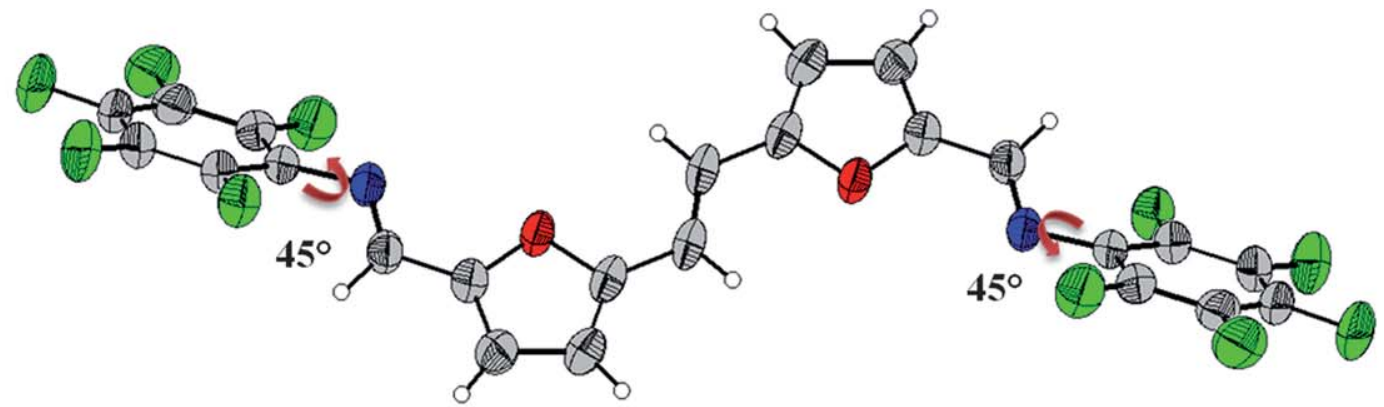

b)

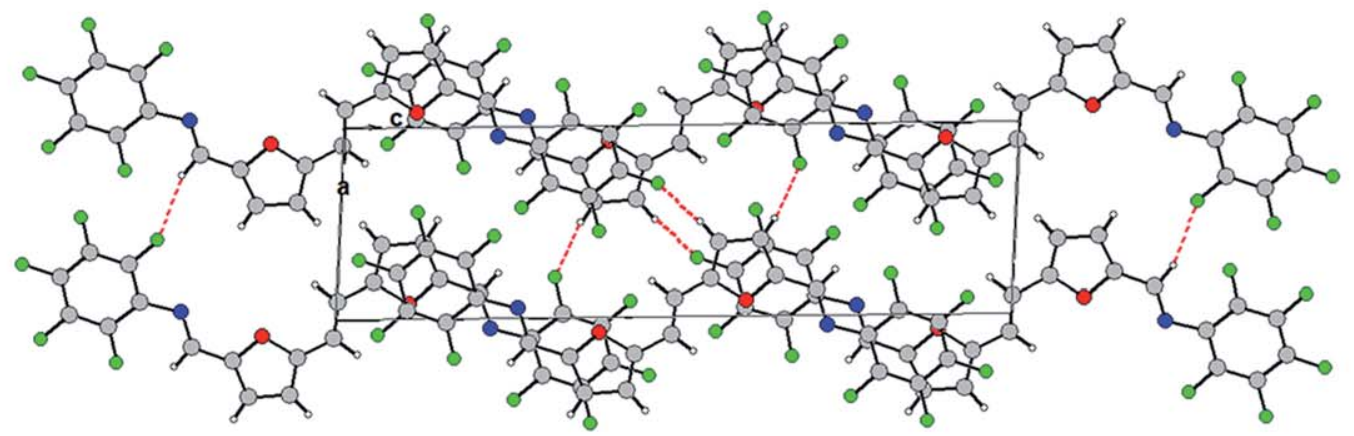

c)

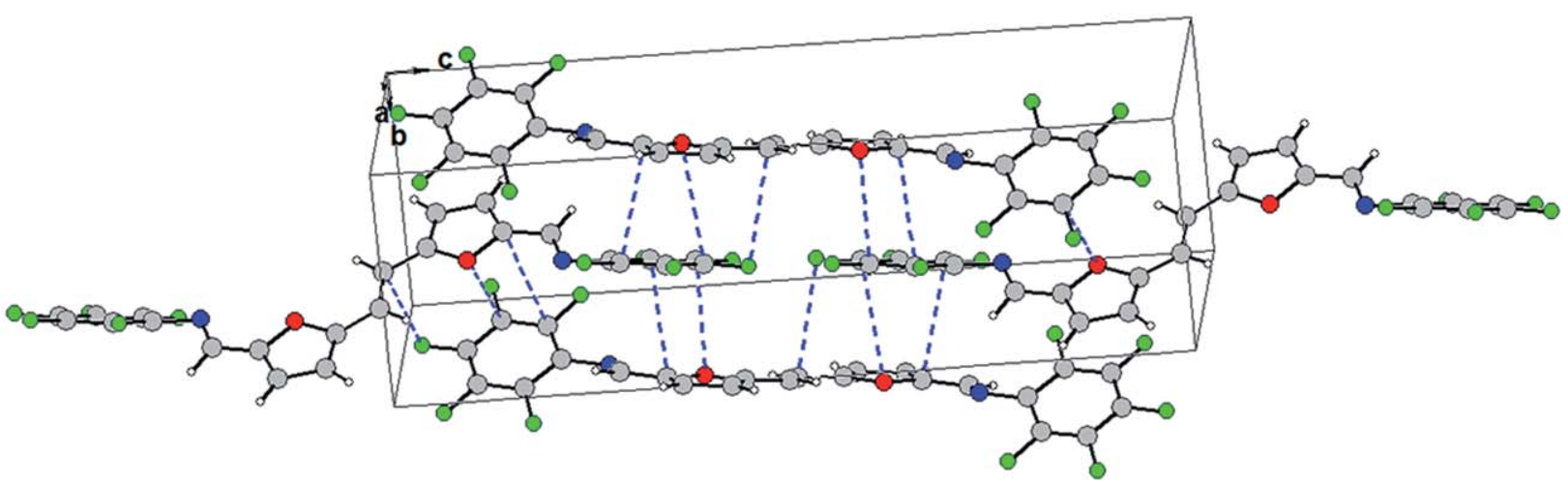

Fig. 3 X-Ray structure of 3: (a) Molecular structure of 3 with anisotropic displacement ellipsoids drawn at the 50\% probability level. (b) Crystal packing of $\mathbf{3}$ showing the intermolecular $\mathrm{C}-\mathrm{H}---\mathrm{F}$ contacts by red dotted lines. (c) Stacking mode in crystal $\mathbf{3}$, the shortest interatomic distances between overlapping molecules are shown by blue dotted lines.

(1.7 mmol) in $2 \mathrm{~mL}$ of $\mathrm{CH}_{2} \mathrm{Cl}_{2}$ and $50 \mathrm{mg}$ of $\mathrm{P}_{2} \mathrm{O}_{5}$. The tube was sealed with a rubber cap and irradiated three times for $10 \mathrm{~min}$ at $80{ }^{\circ} \mathrm{C}$ and under a pressure of 4.4 bar with a power reactor of $200 \mathrm{~W}$. The mixture was cooled to room temperature, poured on $20 \mathrm{~mL}$ of water, extracted twice with $\mathrm{CH}_{2} \mathrm{Cl}_{2}(2 \times 20 \mathrm{~mL})$ and the organic phase was dried on $\mathrm{MgSO}_{4}$. After evaporation of the solvent the residue was purified by flash chromatography on silica gel in the presence of several drops of triethylamine (petroleum ether $\left.\left(40-60{ }^{\circ} \mathrm{C}\right) / \mathrm{CH}_{2} \mathrm{Cl}_{2}, 1 / 1\right)$ to give $125 \mathrm{mg}$ of compound 3 ( $38 \%$ yield).

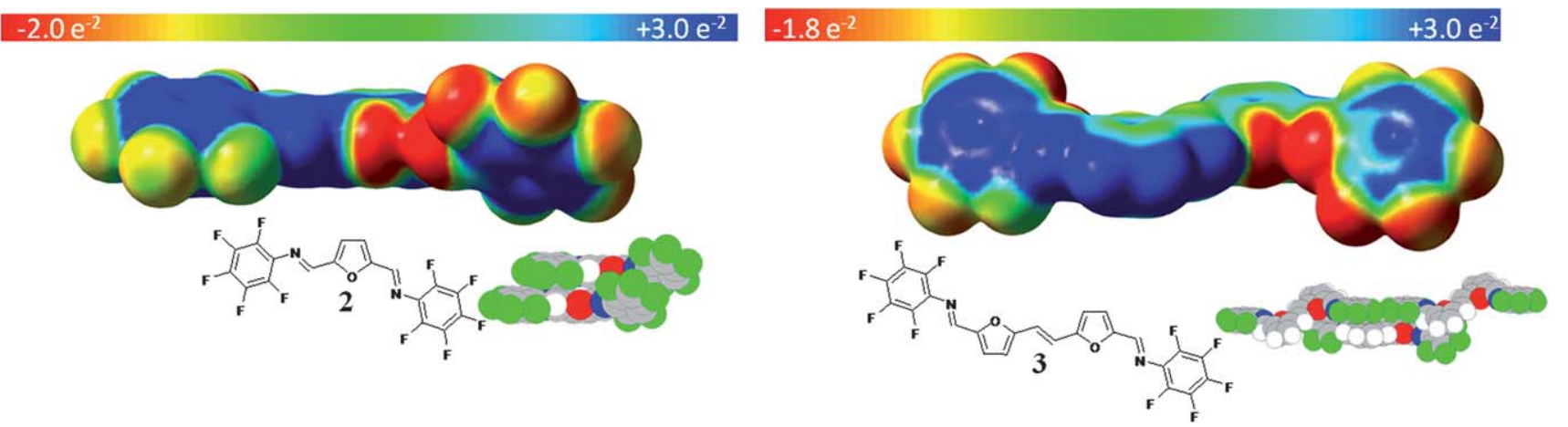

Fig. 4 Electrostatic potential surface of compounds 2 (left) and $\mathbf{3}$ (right), the values are in units of hartree. The overlapping of the molecules is represented in the inset. 
Orange solid, $\mathrm{Mp}=204{ }^{\circ} \mathrm{C}$.

${ }^{1} \mathrm{H}$ NMR $\left(\mathrm{CD}_{3} \mathrm{COCD}_{3}\right): 8.37$ (s, 2H), $7.20(\mathrm{~s}, 2 \mathrm{H}), 7.14(\mathrm{~d}, 2 \mathrm{H}$, $\left.{ }^{3} \mathrm{~J}=3.5 \mathrm{~Hz}\right), 6.65\left(\mathrm{~d}, 2 \mathrm{H},{ }^{3} \mathrm{~J}=3.5 \mathrm{~Hz}\right)$.

${ }^{13} \mathrm{C}$ NMR $\left(\mathrm{CD}_{3} \mathrm{COCD}_{3}\right): 156.7,154.3,150.9,121.9,117.5$, 113.6.

${ }^{19} \mathrm{~F}$ NMR $\left(\mathrm{CD}_{3} \mathrm{COCD}_{3}\right):-153.2(\mathrm{dd}, 4 \mathrm{~F}, J=21 \mathrm{~Hz}, J=6$ $\mathrm{Hz}),-160.3(\mathrm{t}, 2 \mathrm{~F}, J=21 \mathrm{~Hz}),-163.4(\mathrm{td}, 4 \mathrm{~F}, J=21 \mathrm{~Hz}$, $J=6 \mathrm{~Hz}$ ).

MS MALDI-TOF: calcd. for $\mathrm{C}_{24} \mathrm{H}_{8} \mathrm{O}_{2} \mathrm{~N}_{2} \mathrm{~F}_{10}$ 546.06; found $546.95(\mathrm{M}+\mathrm{H})$.

Elemental analysis for $\mathrm{C}_{24} \mathrm{H}_{8} \mathrm{O}_{2} \mathrm{~N}_{2} \mathrm{~F}_{10}$ : calcd. C 52.76, $\mathrm{H} 1.48$, N 5.13; found C 52.18, H 1.41, N 4.96 .

\section{Calculation of electrostatic potential surfaces}

Electrostatic potential surfaces of compounds $\mathbf{2}$ and $\mathbf{3}$ were calculated with Gaussian 09 by using DFT method. From the geometry adopted in the X-ray structures, single-point energy calculations were performed by using the B3LYP/6-31g basis set. Electrostatic potential surfaces were created by using Gausview for a density value of 0.002 electrons per $\mathrm{au}^{3}$.

\section{X-Ray structures}

X-Ray single-crystal diffraction data for the three compounds were collected at $293 \mathrm{~K}$ on a BRUKER KappaCCD diffractometer, equipped with a graphite monochromator utilizing MoK $\alpha$ radiation $(\lambda=0.71073 \AA$ ). The structures were solved by direct methods using SIR92 (Altomare et al., 1993) and refined on $F^{2}$ by full matrix least-squares techniques using SHELXL97 (G.M. Sheldrick, 1998). All non-H atoms were refined anisotropically and the $\mathrm{H}$ atoms were found by Fourier difference synthesis. Absorption was corrected by the SADABS program (Sheldrick, Bruker, 2000) for compound 1 and by Gaussian technique for compounds $\mathbf{2}$ and $\mathbf{3}$.

\section{Acknowledgements}

C. Mallet thanks the Ministry of Education for a $\mathrm{PhD}$ fellowship.

\section{Notes and references}

1 C. B. Aakeroy, N. R. Champness and C. Janiak, CrystEngComm, 2010, 12, 22.

2 G. R. Desiraju, Angew. Chem., Int. Ed., 2007, 46, 8342.

3 M. Fourmigue, Curr. Opin. Solid State Mater. Sci., 2009, 13, 36.

4 O. Ivasenko and D. F. Perepichka, Chem. Soc. Rev., 2011, 40, 191.

5 Y. Z. Wang and A. X. Wu, Chin. J. Org. Chem., 2008, 28, 997.

6 D. Braga and F. Grepioni, Chem. Commun., 2005, 3635.

7 L. R. MacGillivray and J. L. Atwood, Nature, 1997, 389, 469.

8 M. Mas-Torrent and C. Rovira, Chem. Soc. Rev., 2008, 37, 827.

9 A. Pron, P. Gawrys, M. Zagorska, D. Djurado and R. Demadrille, Chem. Soc. Rev., 2010, 39, 2577.

10 C. R. Patrick and G. S. Prosser, Nature, 1960, 187, 1021.

11 J. H. Williams, Acc. Chem. Res., 1993, 26, 593.

12 G. W. Coates, A. R. Dunn, L. M. Henling, J. W. Ziller, E. B. Lobkovsky and R. H. Grubbs, J. Am. Chem. Soc., 1998, 120, 3641.

13 M. L. Renak, G. P. Bartholomew, S. Wang, P. J. Ricatto, R. J. Lachicotte and G. C. Bazan, J. Am. Chem. Soc., 1999, 121, 7787.

14 B. W. Gung and J. C. Amicangelo, J. Org. Chem., 2006, 71, 9261.

15 S. E. Wheeler and K. N. Houk, J. Am. Chem. Soc., 2008, 130, 10854.

16 J. C. Collings, P. S. Smith, D. S. Yufit, A. S. Batsanov, J. A. K. Howard and T. B. Marder, CrystEngComm, 2004, 6, 25.
17 R. Xu, W. Schweizer and H. Frauenrath, Chem.-Eur. J., 2009, 15, 9105 .

18 C.-Z. Li, Y. Matsuo, T. Niinomi, Y. Sato and E. Nakamura, Chem. Commun., 2010, 46, 8582.

19 A. Collas, R. De Borger, T. Amanova and F. Blockhuys, CrystEngComm, 2011, 13, 702.

20 K. Reichenbacher, H. I. Suss and J. Hulliger, Chem. Soc. Rev., 2005, 34, 22.

21 A. Facchetti, M. H. Yoon, C. L. Stern, H. E. Katz and T. J. Marks, Angew. Chem., Int. Ed., 2003, 42, 3900.

22 D. J. Crouch, P. J. Skabara, M. Heeney, I. McCulloch, S. J. Coles and M. B. Hursthouse, Chem. Commun., 2005, 1465.

23 D. J. Crouch, P. J. Skabara, J. E. Lohr, J. J. W. McDouall, M. Heeney, I. McCulloch, D. Sparrowe, M. Shkunov, S. J. Coles, P. N. Horton and M. B. Hursthouse, Chem. Mater., 2005, 17, 6567.

24 J. A. Letizia, A. Facchetti, C. L. Stern, M. A. Ratner and T. J. Marks, J. Am. Chem. Soc., 2005, 127, 13476.

25 C. Videlot-Ackermann, H. Brisset, J. Zhang, J. Ackermann, S. Néon, F. Fages, P. Marsal, T. Tanisawa and N. Yoshimoto, J. Phys. Chem. C, 2009, 113, 1567.

26 M. C. Chen, Y. J. Chiang, C. Kim, Y. J. Guo, S. Y. Chen, Y. J. Liang, Y. W. Huang, T. S. Hu, G. H. Lee, A. Facchetti and T. J. Marks, Chem. Commun., 2009, 1846.

27 C. Kim, M. C. Chen, Y. J. Chiang, Y. J. Guo, J. Youn, H. Huang, Y. J. Liang, Y. J. Lin, Y. W. Huang, T.-S. Hu, G. H. Lee, A. Facchetti and T. J. Marks, Org. Electron., 2010, 11, 801.

28 M. H. Yoon, A. Facchetti, C. E. Stern and T. J. Marks, J. Am. Chem. Soc., 2006, 128, 5792.

29 S. Clement, F. Meyer, J. De Winter, O. Coulembier, C. M. L. Vande Velde, M. Zeller, P. Gerbaux, J.-Y. Balandier, S. Sergeyev, R. Lazzaroni, Y. Geerts and P. Dubois, J. Org. Chem., 2010, 75, 1561.

30 J. A. Letizia, C. Scott, O. Rocio Ponce, F. Antonio, A. R. Mark and J. M. Tobin, Chem.-Eur. J., 2010, 16, 1911.

31 O. Gidron, Y. Diskin-Posner and M. Bendikov, J. Am. Chem. Soc., 2010, 132, 2148.

32 O. Gidron, A. Dadvand, Y. Sheynin, M. Bendikov and D. F. Perepichka, Chem. Commun., 2011, 47, 1976.

33 S. Zhu, Y. Liao and S. Zhu, Org. Lett., 2004, 6, 377.

34 M. Murai, S. Yoshida, K. Miki and K. Ohe, Chem. Commun., 2010, 46, 3366 .

35 M. Benaglia, F. Cozzi, M. Mancinelli and A. Mazzanti, Chem.-Eur. $J ., 2010,16,7456$.

36 The study of the stacking of the molecules in the structure drawn from the data obtained in the Cambridge Database (CSD code WUSKEB) shows an overlapping of the pentafluorophenyl and furan rings. The centroid to centroid distance is $3.586(1) \mathrm{A}$, thus indicating the existence of furan-perfluorophenyl interactions.

37 A. Benahmed-Gasmi, P. Frère and J. Roncali, J. Electroanal. Chem., 1996, 406, 231.

38 E. H. Elandaloussi, P. Frère, A. Benahmed-Gasmi, A. Riou, A. Gorgues and J. Roncali, J. Mater. Chem., 1996, 6, 1859.

39 J. F. Favard, P. Frère, A. Riou, A. BenahmedGasmi, A. Gorgues, M. Jubault and J. Roncali, J. Mater. Chem., 1998, 8, 363.

40 C. Méalares and A. Gandini, Polym. Int., 1996, 40, 33.

41 G. Zotti, A. Randi, S. Destri, W. Porzio and G. Schiavon, Chem. Mater., 2002, 14, 4550.

42 W. G. Skene and S. Dufresne, Org. Lett., 2004, 6, 2949.

43 F.-C. Tsai, C.-C. Chang, C.-L. Liu, W.-C. Chen and S. A. Jenekhe, Macromolecules, 2005, 38, 1958.

44 S. A. P. Guarin, M. Bourgeaux, S. Dufresne and W. G. Skene, J. Org. Chem., 2007, 72, 2631.

45 D. Sek, A. Iwan, B. Jarzabek, B. Kaczmarczyk, J. Kasperczyk, Z. Mazurak, M. Domanski, K. Karon and M. Lapkowski, Macromolecules, 2008, 41, 6653.

46 M. G. Schwab, M. Hamburger, X. Feng, J. Shu, H. W. Spiess, X. Wang, M. Antonietti and K. Mullen, Chem. Commun., 2010, 46, 8932.

47 A. Bolduc, S. Dufresne and W. G. Skene, J. Mater. Chem., 2010, 20, 4820.

48 C. Avelino, I. Sara and V. Alexandra, Chem. Rev., 2007, 107, 2411.

49 J. N. Chheda, G. W. Huber and J. A. Dumesic, Angew. Chem., Int. Ed., 2007, 46, 7164 .

50 J. B. Binder and R. T. Raines, J. Am. Chem. Soc., 2009, 131, 1979.

51 G. A. Halliday, R. J. Young and V. V. Grushin, Org. Lett., 2003, 5, 2003. 
52 K. Tenza, M. J. Hanton and A. M. Z. Slawin, Organometallics, 2009, 28, 4852.

53 S. Lorenzo, G. R. Lewis and I. Dance, New J. Chem., 2000, 24, 295.
54 F. Cozzi, S. Bacchi, G. Filippini, T. Pilati and A. Gavezzotti, Chem.Eur. J., 2007, 13, 7177.

55 T. S. Thakur, M. T. Kirchner, D. Blaser, R. Boese and G. R. Desiraju, CrystEngComm, 2010, 12, 2079. 